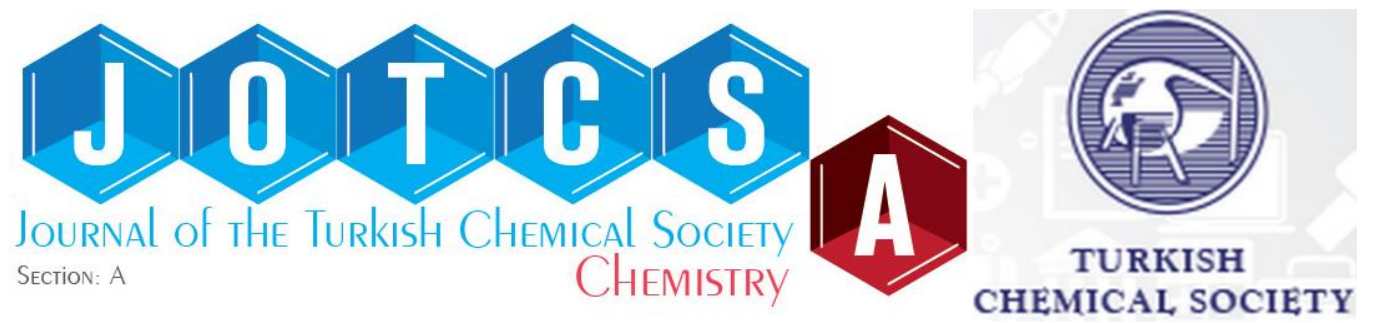

\title{
A Novel Zno Nanoparticle as Drug Nanocarrier in Therapeutic Applications: Kinetic Models and Error Analysis
}

\author{
Selcan Karakuş \\ ${ }^{1}$ Istanbul University-Cerrahpasa, Faculty of Engineering, Department of Chemistry, (34320), Istanbul, \\ Turkey.
}

Abstract: Nanotechnology provides promising possibilities for several biomedical and pharmaceutical applications in the medical industry. Nanostructures play a major role in the recent strategies of technology suitable for novel drug applications. In this work, clindamycin phosphate (CliP) (topical anti-inflammatory drug), xanthan gum (XaG) (biopolymer) and ZnO (zinc oxide) (nanoparticle) nanostructures were synthesized using the sonochemical technique at room temperature. The characterization of the clindamycin phosphate-xanthan gum/ZnO (CliP-XaG/ZnO) nanostructure has been carried out by Fourier transform infrared (FTIR) and X-ray diffraction (XRD). The spectroscopic experiments elucidated the in vitro mechanism of drug delivery system at different $\mathrm{pH}$ media (1.2 and 7.4). In this study, the concentration of the drug in the solution was analyzed by UV-Vis spectrophotometric method and detailed error analysis were performed. The Higuchi gave the best correlation with the experimental data. The swelling behavior of the nanostructure was studied. The percentage of the swelling ratio of $\mathrm{XaG} / \mathrm{ZnO}$ exerted a more significant effect than $\mathrm{XaG}$ at $\mathrm{pH} 1.2$ and $\mathrm{pH} 7.4$. The results show that the capacity of $\mathrm{XaG}$ / ZnO can be preferred as a novel topical anti-inflammatory drug carrier.

Keywords: Xanthan gum, controlled drug delivery, sonochemistry, ZnO, clindamycin phosphate.

Submitted: March 13, 2018. Accepted: .February 26, 2019.

Cite this: Karakuş S. A Novel ZnO Nanoparticle as Drug Nanocarrier in Therapeutic Applications: Kinetic Models and Error Analysis. JOTCSA. 2019;6(2):119-32.

DOI: https://dx.doi.org/10.18596/jotcsa.405505.

*Corresponding author. E-mail: selcan@istanbul.edu.tr. 


\section{INTRODUCTION}

In recent years, novel nanoscale materials (10 to $100 \mathrm{~nm}$ ) are significantly used as a bio-based nanocarrier drug (nanocapsules, nanospheres, micelles, liposomes, and hydrogels) in pharmaceutical technology via storage/delivery controllable mechanism in the therapeutic application. Nanocarrier drug delivery is a progressive strategy of controlled delivery formulations and next generation of therapeutics and it develops with biocompatibility, bioavailability, targeting, and biodistribution because it has many fascinating advantages, such as reduced drug dosage, improved solubility, increased drug loading capacity, low cost, reduced unwanted chemo-toxicity, increased drug-circulation times, and minimum side effects. Metal oxide-based nanocarriers were discovered to be potent for the rising of bioavailability and biocompatibility of poorly aqueous soluble drugs and targeting (1-3).

Biopolymers such as chitosan (4), gelatin (5), alginate (6), xanthan gum (7), gum ghatti (8), and tragacanth gum (9) have been used in drug delivery mechanism owing to their excellent benefits such as biodegradability, nontoxicity, and eco-friendliness. They are employed in a great range of usages such as antibacterial agents, sensor, adsorbent, catalysis, a drug carrier, etc. (10). Physico-chemical properties can be obtained by incorporating an inorganic substance (transporting therapeutic agents) such as metal oxide nanoparticles (11), clay minerals (12), into the biopolymer matrices (13-17). Most drug carriers for drug delivery systems may cause toxicity and immune effects against carriers or therapeutic agents (18).

Xanthan gum is a linear water-soluble extracellular polysaccharide with trisaccharide provided primarily from the bacterium xanthomonas campestris and has significant properties in the delivery systems, due to its biocompatible, biodegradable and non-toxic features (19-21). This study focused on the $\mathrm{Zn}\left(\mathrm{NO}_{3}\right)_{2} \times 6 \mathrm{H}_{2} \mathrm{O}+2 \mathrm{NaOH}$ preparation of $\mathrm{XaG} / \mathrm{ZnO}$ with a controlled CliP delivery kinetics and error analysis. A CliP has an amide, an amine, and a phosphate group and is used as an antibiotic for anaerobic bacterial infections (22-23).

The primary aims of the study were to elucidate the effects of $\mathrm{pH}$-sensitive XaG /metal oxide on the pharmacokinetic properties of a nanostructure, and to determine how changing the efficiency of the drug can effect in vitro drug delivery profiles. XaG was encapsulated on the surface of $\mathrm{ZnO}$ nanoparticles to obtain a new drug carries, and then a drug loading such as CliP was performed. The effects of $\mathrm{ZnO}$ nanoparticles on in vitro drug delivery profiles were studied. It was assumed that adding of $\mathrm{ZnO}$ nanoparticles was possible to change the anti-inflammatory drug delivery mechanism.

\section{EXPERIMENTAL SECTION}

\section{Materials}

Clindamycin phosphate $\left(\mathrm{C}_{18} \mathrm{H}_{34} \mathrm{CIN}_{2} \mathrm{O}_{8} \mathrm{PS}\right.$ ) (ACS Dobfar Tribiano, Italy), xanthan gum (Klamarreagent Co. Ltd., Shanghai, China), zinc nitrate hexahydrate $\left(\mathrm{Zn}\left(\mathrm{NO}_{3}\right)_{2} \times 6 \mathrm{H}_{2} \mathrm{O}\right)$ (Merck), sodium hydroxide (Merck), silica gel (Merck) and buffers (analytical grade).

Formulation of CliP-XaG/ZnO nanostructure CliP-XaG/ZnO nanostructures were synthesized by the sonochemical method at room temperature (frequency $35 \mathrm{kHz}, 320 \mathrm{~W}$, Sonoplus, Bandelin, Germany). A solution of XaG $(0.04 \mathrm{~g} / 50 \mathrm{~mL})$ in water was prepared at $25^{\circ} \mathrm{C}$ in an ultrasonic bath for $60 \mathrm{~min} .10 \mathrm{~mL}$ of $0.002 \mathrm{M}$ $\mathrm{NaOH}$ solution was dropped in $10 \mathrm{~mL}$ of $0.001 \mathrm{M}$ $\mathrm{Zn}\left(\mathrm{NO}_{3}\right)_{2} \times 6 \mathrm{H}_{2} \mathrm{O}$ under continuous magnetic stirring and then homogenized into an ultrasonic bath for $60 \mathrm{~min}$. CliP (0.002 g/50 mL ethanol) was added into the XaG solution and then all solutions were homogenized for $60 \mathrm{~min}$. The nanostructures were dried at $80^{\circ} \mathrm{C}$ to a constant weight and stored at room temperature in a desiccator for analysis (24).

$\mathrm{ZnO}+2 \mathrm{NaNO}_{3}+7 \mathrm{H}_{2} \mathrm{O}$ 


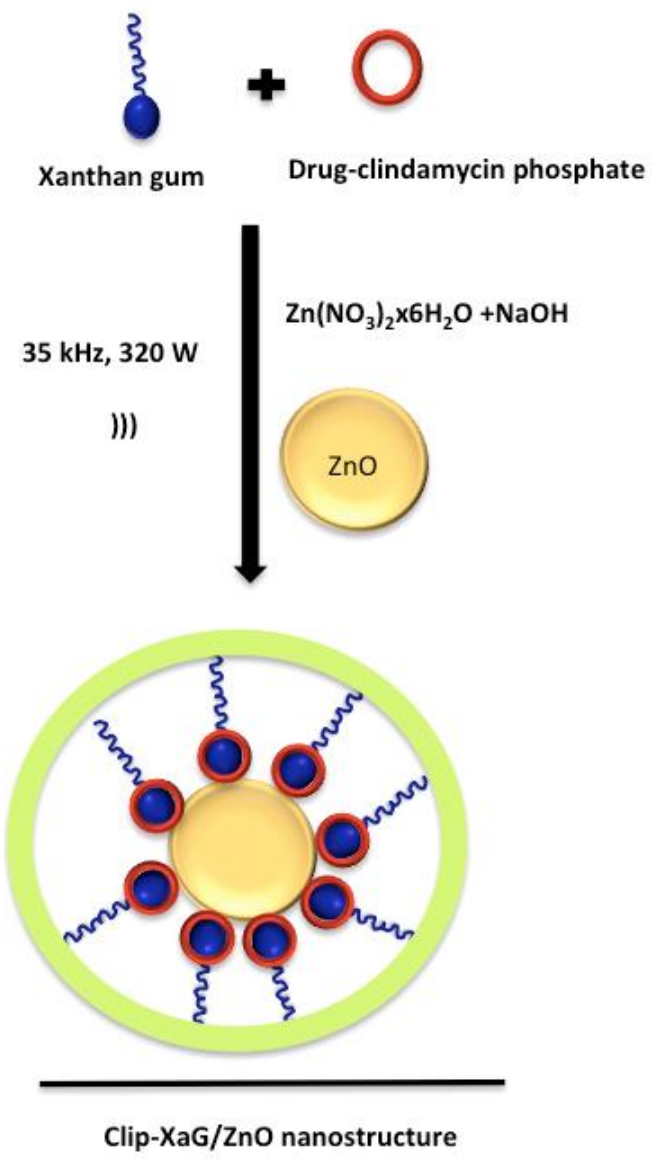

Figure 1: Synthesis of the Clip-XaG/ZnO nanostructure.

\section{Swelling behavior}

The swelling properties of the samples were studied at $\mathrm{pH}$ of 1.2 and 7.4 at $37^{\circ} \mathrm{C} .0 .1 \mathrm{~g}$ of dried samples were immersed in a $50 \mathrm{~mL}$ solution for $6 \mathrm{~h}$ to reach swelling equilibrium. The swelling ratio $(25-26)$ of nanostructures was calculated by the following formula (Eq. 1):

$$
\text { Swelling ratio }(\%)=\frac{\mathrm{W}_{\mathrm{s}}-\mathrm{w}_{\mathrm{d}}}{\mathrm{w}_{\mathrm{d}}} \times 100
$$

$W_{s}$ :the weight of the swollen sample $W_{d}$ :the weight of the dry sample

\section{Kinetic study of drug delivery}

In order to explain the efficacy of the nanostructure, a study of their delivery kinetics is of a major role. The kinetic model for proper the drug delivery mechanism results support to define the delivery profiles. There are several kinetic models, which calculate the overall delivery of drug from the carrier. Generally, five groups are used to understand the controlled kinetics of drug delivery mechanisms such as empirical erosion mathematical models (Hopfenberg model and Cooney model), diffusion and chemical reaction based models (Non-Monte Carlo model and Monte Carlo model), statistical methods (Exploratory Data Analysis Method and Multivariate approach or Multivariate analysis of variance (MANOVA)), model-dependent methods (Zero-order kinetics, First-order kinetics, Higuchi model, Ritger-Peppas and Korsmeyer-Peppas model (Power law), Brazel and Peppas model, Hixson Crowell model or cube root law, Baker Lonsdale model, Peppas-Sahlin model, Weibull model, Gompertz model and Regression analysis) (Table 1), and model-independent approach. The main difference between model-independent approach (MIA) and model-dependent approach (MDA) lies in the fact that, while MIA can be calculated from the mean residence time of the drug in the dosage form, the latter requires prior adjustment of the data to a model that describes its temporal evolution. Model-dependent methods are based on different mathematical equations, are very useful to describe the release profile (2735).

Table 1: A Linearized form of the kinetic models.

\begin{tabular}{ccc}
\hline Equations & Kinetic models & Ref \\
\hline $\mathrm{Q}_{\mathrm{t}}=\mathrm{Q}_{0}+\mathrm{K}_{0} \cdot \mathrm{t}$ & Zero order model & $(29)$ \\
$\mathrm{In} \mathrm{Q}_{\mathrm{t}}=\ln _{0}+\mathrm{K}_{1} \cdot \mathrm{t}$ & First order model & $(30)$ \\
$\mathrm{Q}_{\mathrm{t}}=\mathrm{Q}_{0}+\mathrm{K}_{\mathrm{H}} \cdot \mathrm{t}^{1 / 2}$ & Higuchi model & $(31)$ \\
$\mathrm{Q}_{\mathrm{t}}=\mathrm{Q}_{0}+\mathrm{K}_{\mathrm{KP}} \cdot \mathrm{t}_{\mathrm{n}}$ & Korsmeyer-Peppas & $(32)$ \\
$\mathrm{Q}_{0}^{1 / 3}-\mathrm{Q}_{\mathrm{t}}^{1 / 3}=\mathrm{K}_{\mathrm{S}} \cdot \mathrm{t}$ & Hixson-Crowell & $(33)$ \\
$\mathrm{f}_{\mathrm{t}}=3 / 2\left[1-\left(1-\mathrm{M}_{\mathrm{t}} / \mathrm{M} \infty\right)^{2 / 3}\right]-\mathrm{M}_{\mathrm{t}} / \mathrm{M} \infty=\mathrm{k} . \mathrm{t}$ & Baker-Lonsdale & $(34)$ \\
\hline
\end{tabular}


$Q_{t}$ or $M_{t}$ : the amount of drug released in time $t$, $\mathrm{Q}_{0}$ : the initial amount of drug, Mo : the amount of drug released in equilibrium. $\mathrm{K}_{0}$ : zero order kinetic constant, $\mathrm{K}_{1}$ : first order kinetic constant, $\mathrm{K}_{\mathrm{H}}$ : Higuchi kinetic constant, $\mathrm{K}_{\mathrm{KP}}$ : KorsmeyerPeppas release constant, $\mathrm{K}_{\mathrm{S}}$ : Hixson-Crowell kinetic constant $\mathrm{n}$ : diffusional release exponent $\mathrm{t}$ time.

\section{Characterization}

An X-ray diffractometer (Bruker D8 Advance Xray Diffractometer) was used with CuKa $(\lambda=$ $0.15418 \mathrm{~nm}, 40 \mathrm{kV}, 40 \mathrm{~mA}$ ) radiation over a range of $2 \theta$ angles from 2 to 75 , with a step size of $0.02 \%$ s. The surface morphology of nanocarrier was investigated using a Scanning Electron Microscope (SEM, Quanta FEG 450). FTIR spectroscopy was recorded using the Perkin Elmer FTIR emission spectrometer (Spectrum Two) and nanostructures were properly ground with $\mathrm{KBr}$ powder and were analyzed from 4000 to $600 \mathrm{~cm}^{-1}$ frequency range with a resolution of 4 $\mathrm{cm}^{-1}$ and 8 scans. UV-Vis spectrophotometry was performed on Perkin Elmer (Perkin Elmer, Lambda 35) device using a pair of quartz cuvettes $(12.4 * 12.4 * 45 \mathrm{~mm})$.

\section{RESULTS AND DISCUSSION}

\section{Swelling behavior}

In drug delivery mechanisms the delivery rate of the $\mathrm{pH}$-sensitive drug is changed with several different parameters as the swelling ratio, drugmatrix effect, amount of sample, $\mathrm{pH}$, viscosity, and the initial concentration. The viscosity and $\mathrm{pH}$ of XaG with different concentration (0.01-0.05 $\mathrm{g} / 50 \mathrm{~mL}$ ) and the swelling ratio (SR) of XaG and $\mathrm{Xa} / \mathrm{ZnO}$ in different $\mathrm{pH}$ buffer solutions are shown in Fig. 2-4.

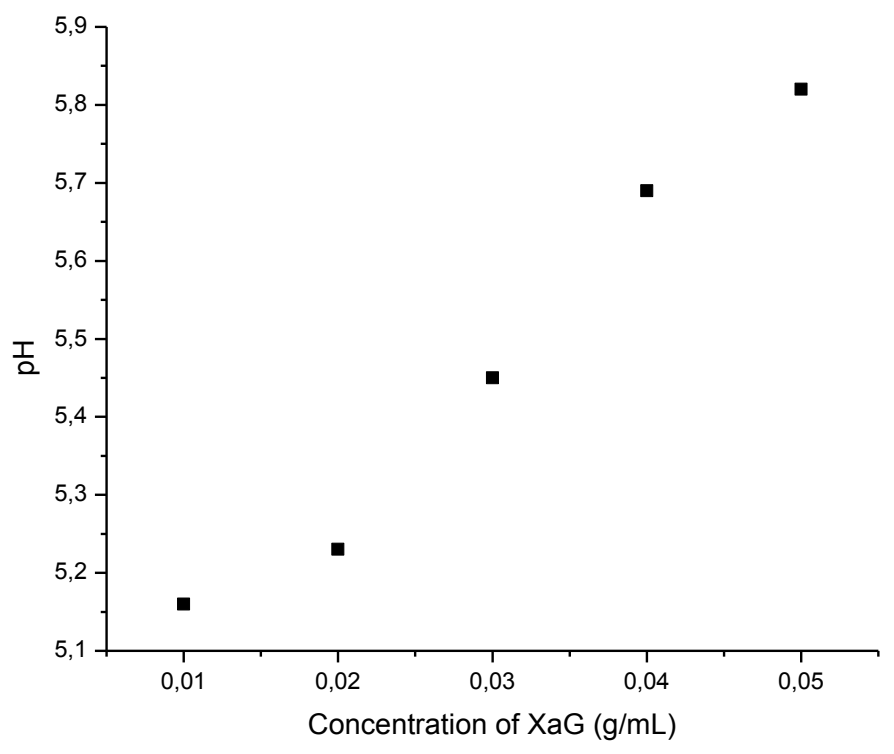

Figure 2: The viscosity of XaG with different concentration (0.01-0.05 g / $50 \mathrm{~mL})$ ). 


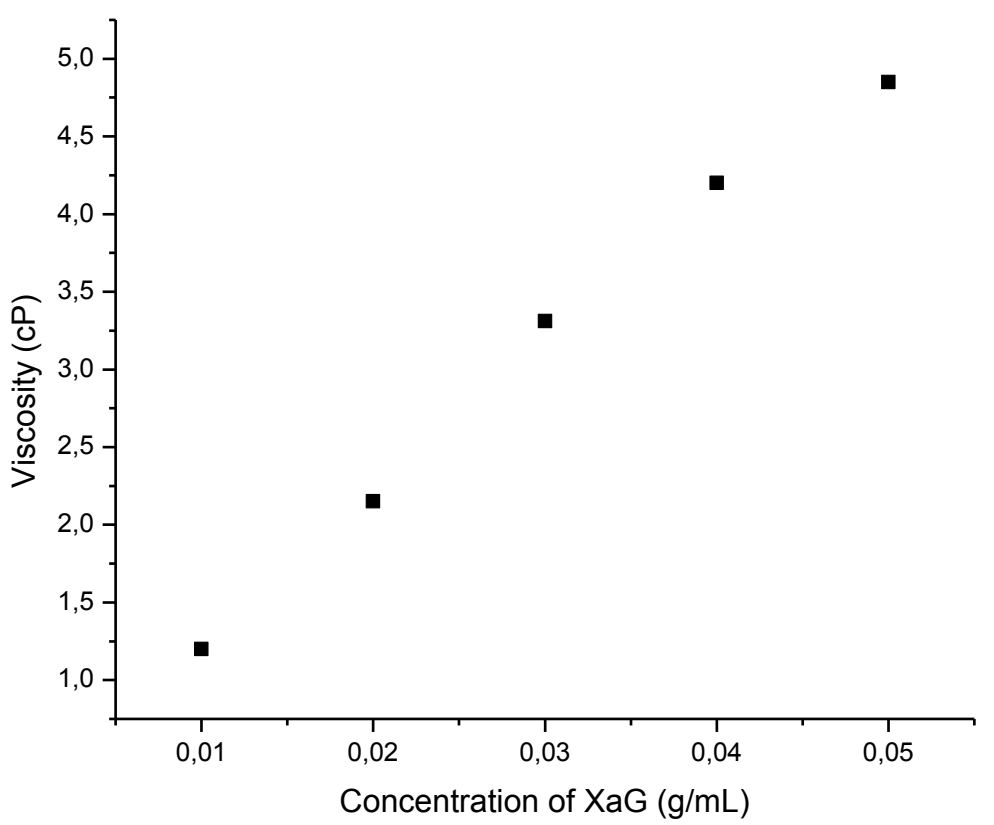

Figure 3: $\mathrm{pH}$ of $\mathrm{XaG}$ with different concentration (0.01-0.05 g / $50 \mathrm{~mL})$ ).

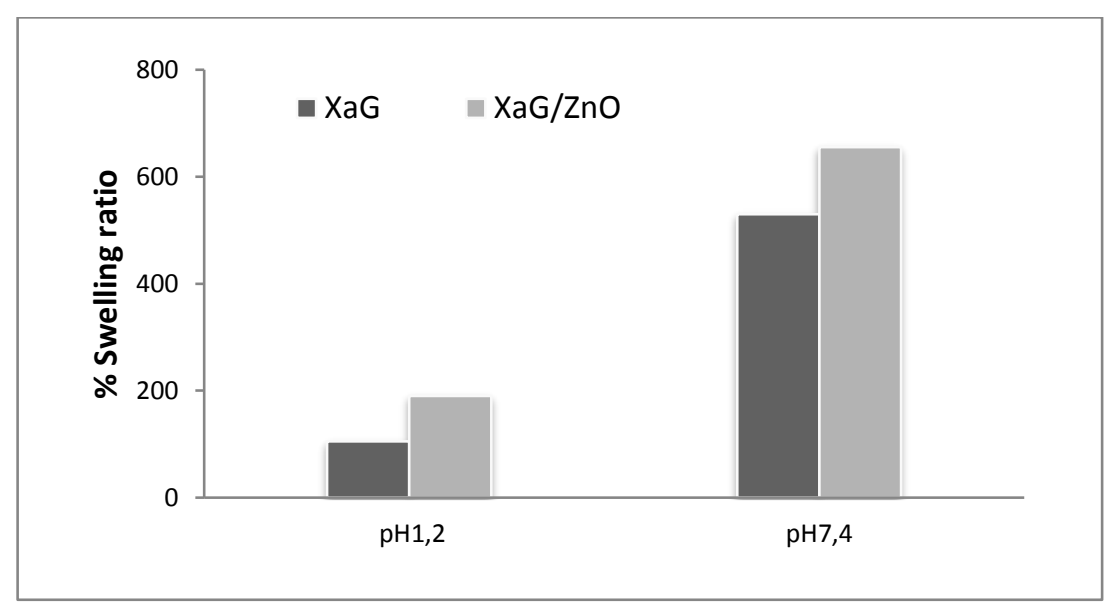

Figure 4: The swelling ratio of the samples.

The percentage of the swelling ratio (\%) of XaG and $\mathrm{XaG} / \mathrm{ZnO}$ increased with time and reached equilibrium in the 3rd hour. The swelling equilibrium values for $\mathrm{XaG}$ and $\mathrm{XaG} / \mathrm{ZnO}$ were found as $105 \%, 190 \%$ at $\mathrm{pH} 1.2$ and $530 \%$, $655 \%$ at $\mathrm{pH} 7.4$, respectively. The addition of $\mathrm{ZnO}$ in a polymer matrix increased the swelling. This result was based on the electrostatic repulsive force between functional groups and was related to the $\mathrm{ZnO}$ has moved as an added crosslinking agent (36).

\section{Drug delivery studies}

The drug delivery kinetic models for the nanostructure were applied in buffer solutions ( $\mathrm{pH} 1.2$ and 7.4$)$ at $37 \pm 0.5{ }^{\circ} \mathrm{C}$ with continuous stirring for $6 \mathrm{~h}$. As shown in Figure 1 , the drug delivery shows a typical $\mathrm{pH}$-sensitive delivery proceeding: faster in neutral and slower in the acidic environment and coherent with the experimental data reported by Honglin Luo and co-workers (37).

In this study, to comprehend the drug delivery kinetic mechanism, the results were examined with different kinetic models such as zero-order kinetics, first-order kinetics, Higuchi model, Korsmeyer-

Peppas model (Power law), Hixson Crowell model or cube root law and Baker Lonsdale model. Kinetic models emphasizing on different release phenomena were used to fit the drug release profile with the aid of Origin 8 software (Table 2 ).

In this study, the drug delivery profiles could be best explained by the Higuchi model $\left(R^{2}=0.936-\right.$ $0.981)$. The XaG $(2.5 \mathrm{~g} / \mathrm{L})$ and $\mathrm{XaG} / \mathrm{ZnO}(2.5 \mathrm{~g} / \mathrm{L})$ exhibited Qt $(\mathrm{mg} / \mathrm{g})$ of 495 and 597, respectively during the initial $6 \mathrm{~h}$ of equilibration in neutral medium (Figs. 5-6). These values for each model 
were given in Table 2. It is shown that the delivery kinetics are changed with the addition of ZnO nanoparticles which exhibited a major effect on the rate of drug delivery. Such results of drug delivery are based on the higher surface area and distribution of nanoparticles.

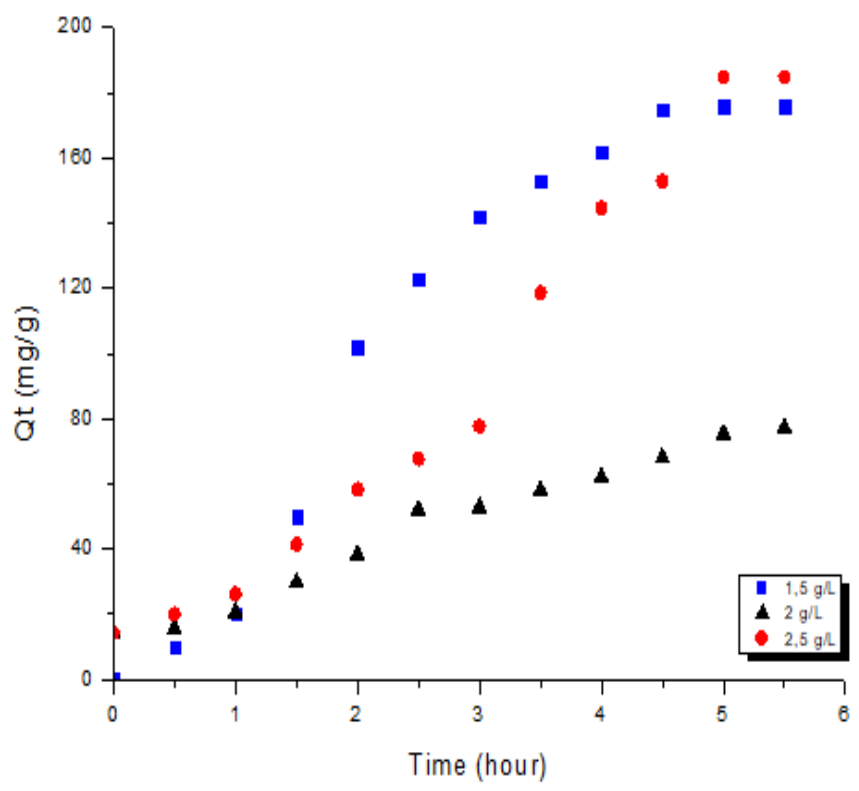

Figure 5: Amount of released drug as a function of time $(1.5 \mathrm{~g} / \mathrm{L}-2.5 \mathrm{~g} / \mathrm{L}$ of drug loaded, released at $\mathrm{pH} 1.2)$.

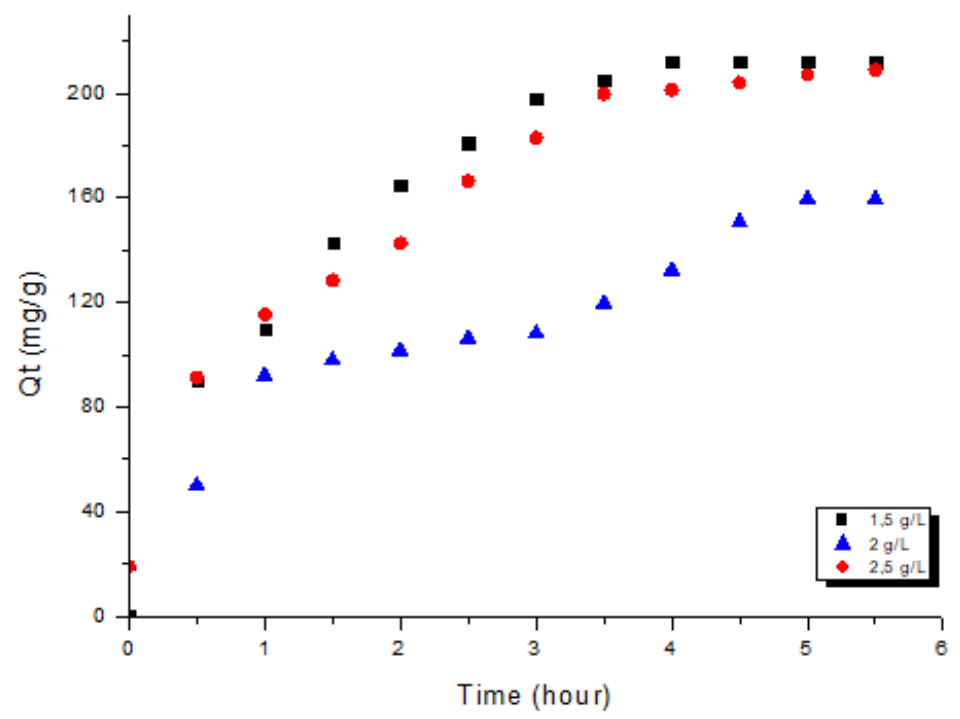

Figure 6: Amount of released drug as a function of time $(1.5 \mathrm{~g} / \mathrm{L}-2.5 \mathrm{~g} / \mathrm{L}$ of drug loaded, released at $\mathrm{pH} 7.4$ ).

\section{Morphology and structure}

$X R D$ analysis

XRD analysis was performed to understand the morphological characteristics of a nanostructure. The XRD patterns of the XaG/ZnO and CliP$\mathrm{XaG} / \mathrm{ZnO}$ were shown in Figure 7 . The size of the ZnO nanoparticle was determined using Scherr's equation (38).

$$
D=k \lambda /(\beta \operatorname{Cos} \theta)
$$

is $0.154 \mathrm{~nm}$ and $\beta$ is the full width at half maximum. Results match well with those of $\mathrm{ZnO}$ and approve the formation of $\mathrm{ZnO}$ nanoparticles in the polymer matrix with the support Match 3 software. In X-ray diffractogram, diffractions of

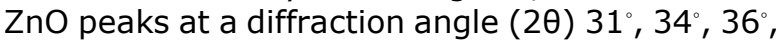
$47^{\circ}, 56^{\circ}, 63^{\circ}$ and $67^{\circ}$ were obtained in both $\mathrm{XaG} / \mathrm{ZnO}$ and CliP-XaG/ZnO. The crystallite size of $\mathrm{ZnO}$ is $\sim 20 \mathrm{~nm}$ in CliP-XaG/ZnO.

where $D$ is the crystallite size in $n m, k$ is $0.89, \lambda$ 
Table 2: Comparison of different kinetic model parameters of clindamycin phosphate-xanthan gum/ZnO at $37{ }^{\circ} \mathrm{C}$.

\begin{tabular}{|c|c|c|c|c|c|c|c|c|c|c|c|c|c|}
\hline \multirow[b]{2}{*}{$\mathrm{pH}$} & \multirow[b]{2}{*}{$\mathrm{g} / \mathrm{L}$} & \multicolumn{2}{|c|}{ Zero Order } & \multicolumn{2}{|c|}{ First Order } & \multicolumn{2}{|c|}{ Higuchi } & \multicolumn{2}{|c|}{ Hixson-Crowell } & \multicolumn{2}{|c|}{ Baker-Lonsdale } & \multicolumn{2}{|c|}{ Peppas } \\
\hline & & $\mathrm{R}^{2}$ & $\mathrm{~K}\left(\mathrm{~h}^{-}\right)$ & $\mathrm{R}^{2}$ & $\mathrm{~K}$ & $\mathbf{R}^{2}$ & $\mathbf{K}_{\mathbf{H}}$ & $\mathrm{R}^{2}$ & $\mathrm{~K}_{\mathrm{s}}$ & $\mathrm{R}^{2}$ & $\mathrm{~K}$ & $\mathrm{R}^{2}$ & $\mathrm{~N}$ \\
\hline 1.2 & 1.5 & 0.871 & 46.90 & 0.903 & 0.242 & 0.946 & 141.39 & 0.885 & 0.159 & 0.930 & 0.07 & 0.398 & 0.063 \\
\hline 1.2 & 2 & 0.921 & 43.70 & 0.966 & 0.162 & 0.936 & 192.31 & 0.779 & 0.159 & 0.905 & 0.03 & 0.697 & 0.030 \\
\hline 1.2 & 2.5 & 0.912 & 63.18 & 0.860 & 0.183 & 0.963 & 204.28 & 0.916 & 0.136 & 0.938 & 0.08 & 0.483 & 0.076 \\
\hline 7.4 & 1.5 & 0.893 & 35.98 & 0.730 & 0.508 & 0.965 & 130.04 & 0.927 & 0.134 & 0.915 & 0.08 & 0.972 & 1.607 \\
\hline 7.4 & 2 & 0.963 & 42.97 & 0.818 & 0.518 & 0.986 & 147.71 & 0.974 & 0.111 & 0.891 & 0.07 & 0.967 & 1.433 \\
\hline 7.4 & 2.5 & 0.967 & 85.02 & 0.833 & 0.558 & 0.981 & 289.95 & 0.975 & 0.1741 & 0.676 & 0.06 & 0.972 & 1.6071 \\
\hline
\end{tabular}



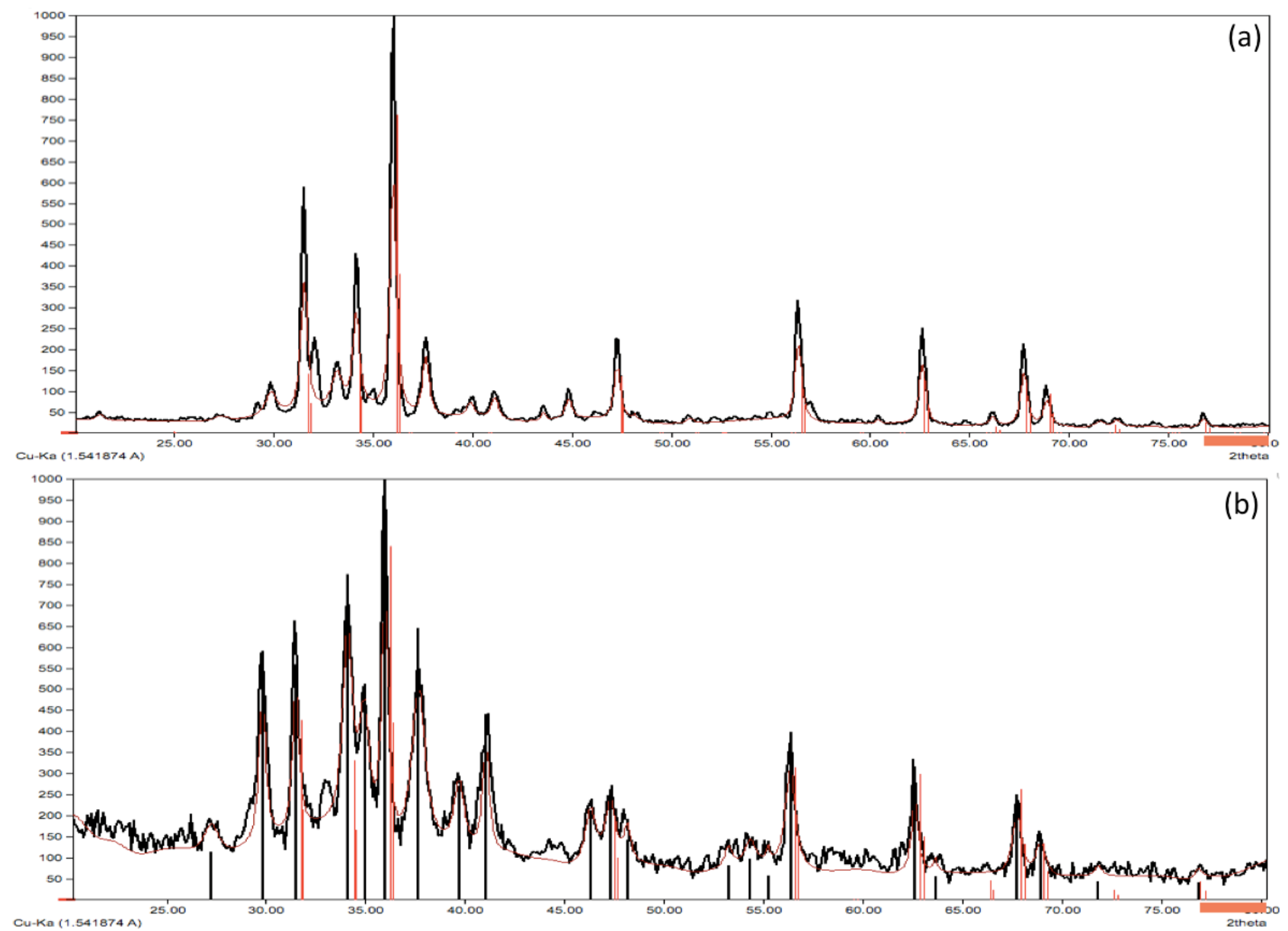

Figure 7: The XRD pattern of XaG/ZnO (a) and CliP-XaG/ZnO (b).

\section{FTIR analysis}

The chemical interactions between drug and XaGZnO nanoparticles were studied by FTIR analysis (Figure 8). In FTIR spectra, all the characteristic peaks of XaG were observed at $3267 \mathrm{~cm}^{-1}(-\mathrm{OH})$, at $1594.4 \mathrm{~cm}^{-1}$ ( $\mathrm{C}=\mathrm{O}$ stretching) and at 1369.7 $\mathrm{cm}^{-1}$ (C-H stretching) peaks. FTIR spectrum of
XaG-ZnO was found a very intense band below $500 \mathrm{~cm}^{-1}$ related to the stretching vibration of $\mathrm{ZnO}$ bond and was observed at $1690.6 \mathrm{~cm}^{-1}$ ( $C=0$ stretching), $1620.5 \mathrm{~cm}^{-1}$ ( $C=C$ stretching), $1350.8 \mathrm{~cm}^{-1}(\mathrm{C}-\mathrm{H}$ bending) peaks which are in agreement with Hashemi et al. (39) and Benichou et al. (40). 


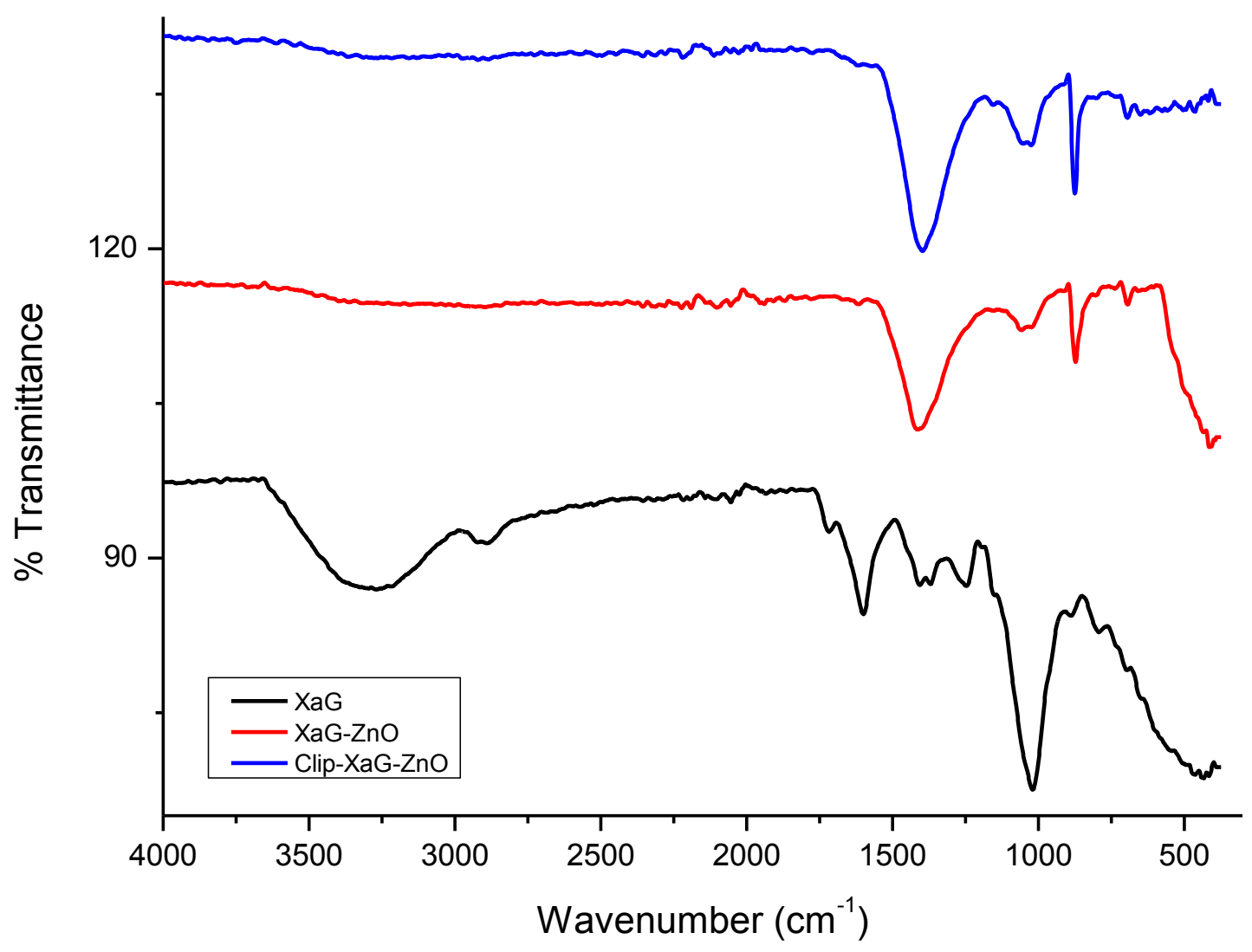

Figure 8: Infrared spectroscopy (ATR-IR) data for XaG, XaG/ZnO and CliP-XaG/ZnO.

SEM analysis

The Scanning electron microscope (SEM) micrographs performed on the internal structure was used to observe the distribution of the $\mathrm{ZnO}$ particles in the XaG and Clip-XaG (Fig.9). It was monitored that the hydroxides on the surface of the $\mathrm{ZnO}$ particles tended to interact with $\mathrm{XaG}$ as a cubic structure at a diameter larger than 443 $\mathrm{nm}$ and to interact with Clip-XaG as a spherical structure. And also a relatively well dispersion of $\mathrm{ZnO}$ nanoparticles in drug-polymer matrix was observed. The experimental results showed that the drug-polymer matrix encapsulated some of the $\mathrm{ZnO}$ particles through van der Waals coagulates. 

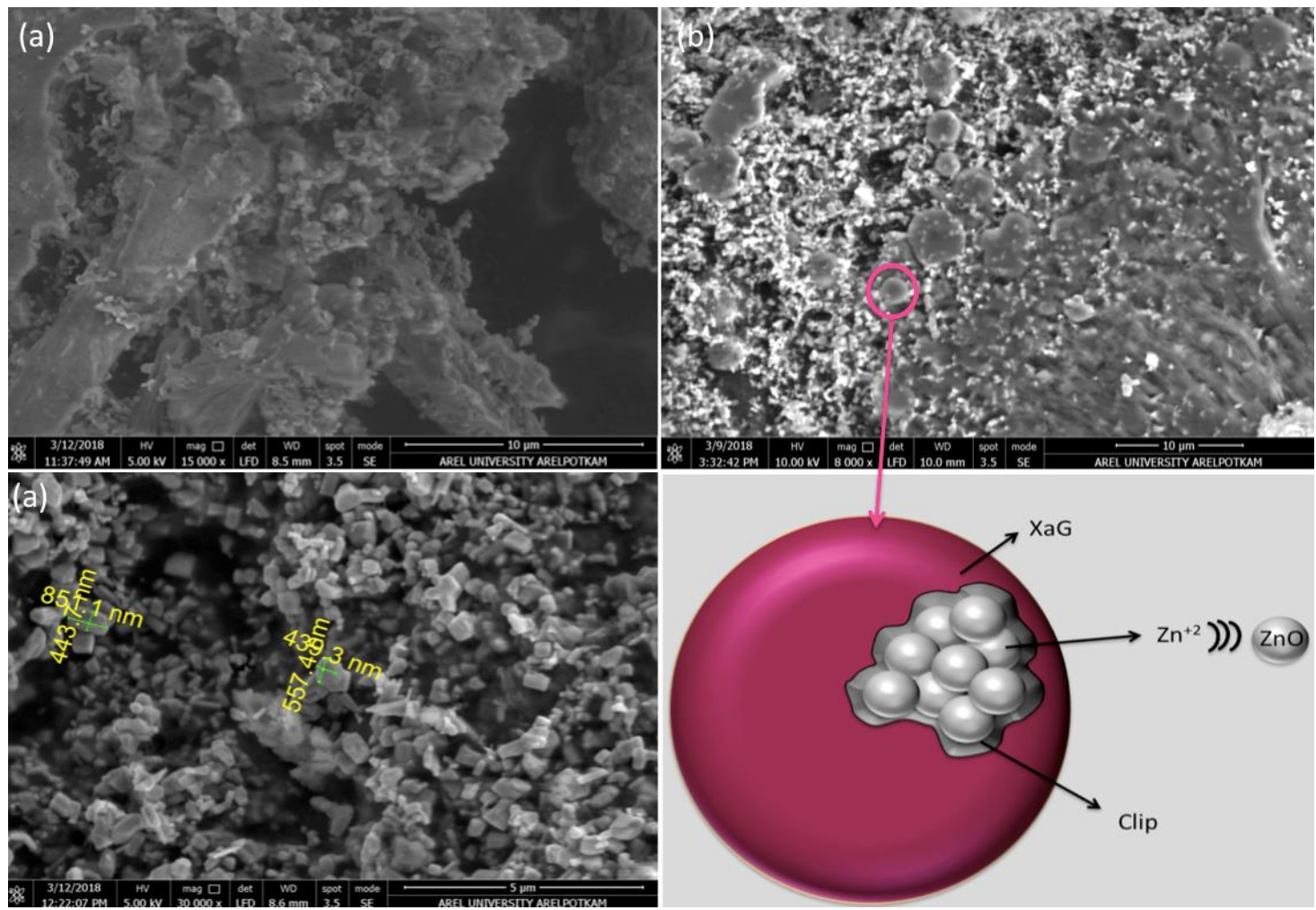

Figure 9: SEM images on the surface of (a) XaG/ZnO and (b) CliP-XaG/ZnO.

The SEM-EDX mapping of $\mathrm{Zn}, \mathrm{C}$ and $\mathrm{O}$ elements on the surface of the samples shown in Figure 10 approve the dispersal of $\mathrm{ZnO}$ nanoparticles and the formation of nanostructures.
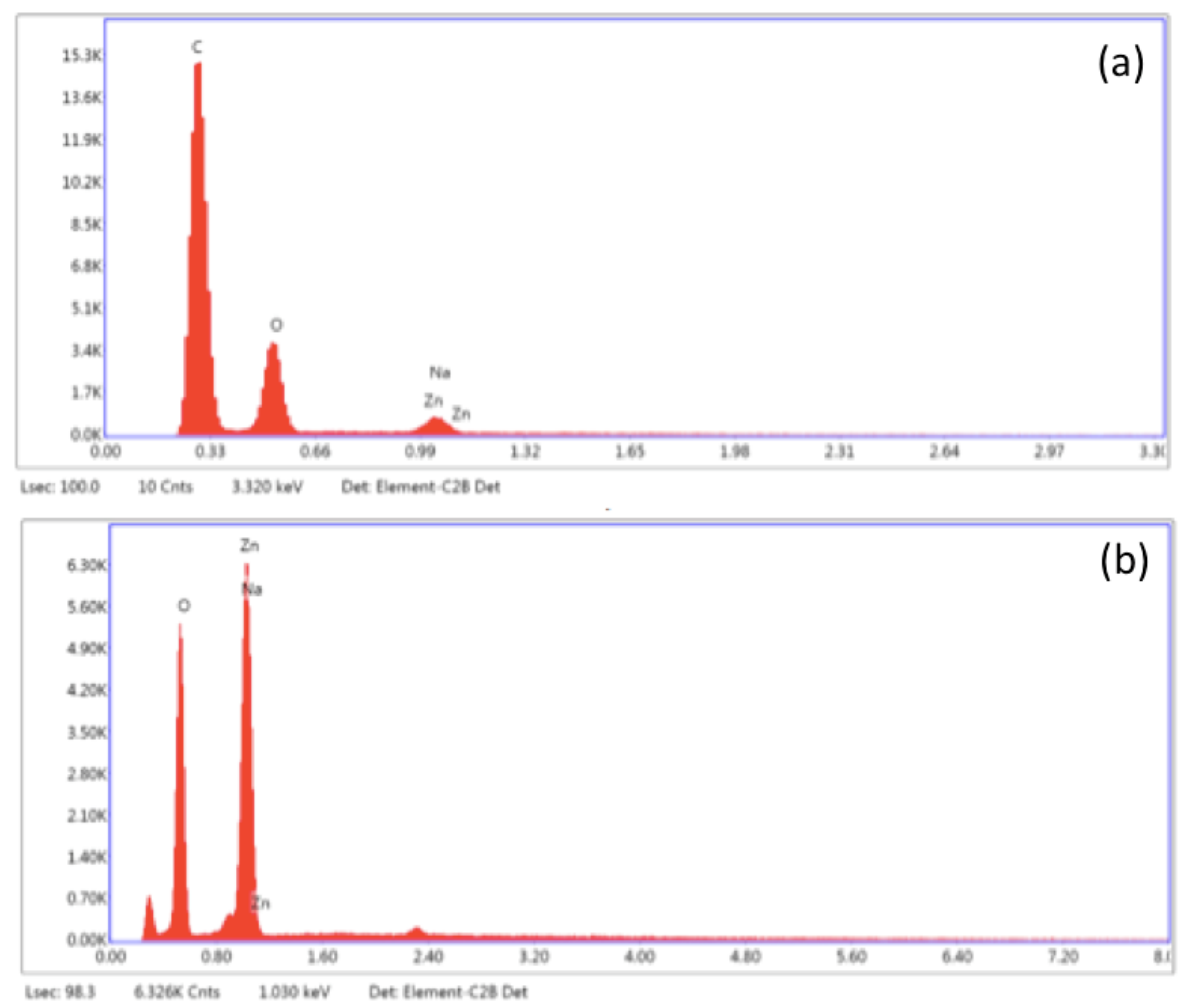

Figure 10: SEM-EDX spectra of (a) XaG/ZnO and (b) CliP-XaG/ZnO.

\section{Error analysis methods of kinetic models}

The application of $\mathrm{R}^{2}$ is not enough to understand linear drug delivery kinetic models, which evaluates the distinction between experimental and theoretical data. Therefore, we calculated five error analysis methods for identifying of model parameters in this study which were the sum of squares of errors (SSE), The hybrid fractional error function (HYBRID), Marquart's percentage standard deviation (MPSD), The 
average relative error (ARE), and the sum of the absolute errors (EABS), respectively (Table 3 ) (41-45).

Table 3: The names and equations of error analysis methods.

\begin{tabular}{ccc}
\hline Equations & Error models & Ref \\
\hline$\sum_{i=1}^{n}\left(q_{\mathrm{e}, \mathrm{calc}}-q_{\mathrm{e}, \text { meas }}\right)_{i}^{2}$ & SSE
\end{tabular}

qe,meas: measured capacity,

qe, cal:calculated capacity,

$\mathrm{n}$ : number of data points

p: number of parameters.

In this study, we understand that the most clear result from these models is the Higuchi kinetic model in the lowest amounts for the error parameters (Table 4) and therefore fits the data better than the rest of the drug delivery kinetic models.

\section{CONCLUSIONS}

Comparison of the drug delivery rate profiles of $\mathrm{XaG} / \mathrm{ZnO}$ by using different types of models showed the highest Qt $(\mathrm{mg} / \mathrm{g})$ of the drug carrier at $\mathrm{pH}$ 7.4. The parameters of a kinetic model are that the kinetic mechanism displays just diffusion controlled drug delivery from non-degradable panels, the drug is first distributed in a homogeneous phase. The experimental data show that the capacity of $\mathrm{XaG} / \mathrm{ZnO}$ can be preferred as a novel topical anti-inflammatory drug carrier.

Table 4: Error analysis of the different kinetic models of clindamycin phosphate-xanthan gum/ZnO.

\begin{tabular}{|c|c|c|c|c|}
\hline $\mathrm{pH}$ & & Zero Order & First Order & Higuchi \\
\hline \multirow{5}{*}{1.2} & SSE & 178395,6 & 139434,9 & 840,85 \\
\hline & HYBRID & 492,34 & 360,19 & 370,56 \\
\hline & MPSD & 1,54 & 1,63 & 0,08 \\
\hline & ARE & 2,12 & 2,76 & 1,5 \\
\hline & EABS & 718,58 & 821,24 & 536,5 \\
\hline \multirow{5}{*}{7.4} & SSE & 291080 & 398745 & 970,85 \\
\hline & HYBRID & 706,48 & 900,596 & 320,56 \\
\hline & MPSD & 2,34 & 2,74 & 0,07 \\
\hline & ARE & 2,65 & 2,86 & 1,2 \\
\hline & EABS & 828 & 937 & 345,6 \\
\hline
\end{tabular}




\section{ACKNOWLEDGEMENTS}

This work was supported by the research fund of Istanbul University project number 25049. The author acknowledges the support on SEM analysis from ArelPOTKAM, Istanbul.

\section{REFERENCES}

1. Zhang $\mathrm{Y}$, Chan $\mathrm{HF}$, Leong $\mathrm{KW}$. Advanced materials and processing for drug delivery: The past and the future. Advanced Drug Delivery Reviews. 2013 Jan;65(1):104-20.

2. Treesuppharat W, Rojanapanthu $P$, Siangsanoh C, Manuspiya H, Ummartyotin S. Synthesis and characterization of bacterial cellulose and gelatinbased hydrogel composites for drug-delivery systems. Biotechnology Reports. 2017 Sep; 15:84-91.

3. Zhao L, Shen G, Ma G, Yan X. Engineering and delivery of nanocolloids of hydrophobic drugs. Advances in Colloid and Interface Science. 2017 Nov;249:308-20.

4. Shariatinia Z, Zahraee Z. Controlled release of metformin from chitosan-based nanocomposite films containing mesoporous MCM-41 nanoparticles as novel drug delivery systems. Journal of Colloid and Interface Science. 2017 Sep;501:60-76.

5. K.S. J, S. S, Kalarikkal N, Pothen LA, Thomas S. Gelatin modified lipid nanoparticles for antiviral drug delivery. Chemistry and Physics of Lipids. 2017 Oct;207:24-37.

6. Ribeiro LNM, Alcântara ACS, Darder M, Aranda P, Herrmann PSP, Araújo-Moreira FM, et al. Bionanocomposites containing magnetic graphite as potential systems for drug delivery. International Journal of Pharmaceutics. 2014 Dec;477(1-2):553-63.

7. Park S, Mun S, Kim Y-R. Effect of xanthan gum on lipid digestion and bioaccessibility of $\beta$ carotene-loaded rice starch-based filled hydrogels. Food Research International. 2018 Mar;105:440-5.

8. Sharma K, Kumar V, Chaudhary B, Kaith BS, Kalia S, Swart HC. Application of biodegradable superabsorbent hydrogel composite based on Gum ghatti-co-poly(acrylic acid-aniline) for controlled drug delivery. Polymer Degradation and Stability. 2016 Feb;124:101-11.

9. Sadat Hosseini M, Hemmati K, Ghaemy M. Synthesis of nanohydrogels based on tragacanth gum biopolymer and investigation of swelling and drug delivery. International Journal of Biological Macromolecules. 2016 Jan;82:806-15.
10. Zare-Akbari Z, Farhadnejad H, Furughi-Nia B, Abedin S, Yadollahi M, Khorsand-Ghayeni M. PHsensitive bionanocomposite hydrogel beads based on carboxymethyl cellulose/ZnO nanoparticle as drug carrier. International Journal of Biological Macromolecules. 2016 Dec; $93: 1317-27$.

11. Ay AN, Konuk D, Zümreoğlu-Karan B. Magnetic nanocomposites with drug-intercalated layered double hydroxide shell supported on commercial magnetite and laboratory-made magnesium ferrite core materials. Materials Science and Engineering: C. 2011 Jul;31(5):8517.

12. Oliveira AS, Alcântara ACS, Pergher SBC. Bionanocomposite systems based on montmorillonite and biopolymers for the controlled release of olanzapine. Materials Science and Engineering: C. 2017 Jun;75:12508.

13. Zhang $M$, Liu J, Kuang $Y$, Li Q, Zheng D-W, Song $\mathrm{Q}$, et al. Ingenious $\mathrm{pH}$-sensitive dextran/mesoporous silica nanoparticles based drug delivery systems for controlled intracellular drug release. International Journal of Biological Macromolecules. 2017 May;98:691-700.

14. El-Naggar AWM, Senna MM, Mostafa TA, Helal $\mathrm{RH}$. Radiation synthesis and drug delivery properties of interpenetrating networks (IPNs) based on poly(vinyl alcohol)/ methylcellulose blend hydrogels. International Journal of Biological Macromolecules. 2017 Sep;102:104551.

15. Bajpai SK, Jadaun $M$, Bajpai $M$, Jyotishi $P$, Shah FF, Tiwari $S$. Controlled release of Doxycycline from gum acacia/poly(sodium acrylate) microparticles for oral drug delivery. International Journal of Biological Macromolecules. 2017 Nov;104:1064-71.

16. Wang R, Shou D, Lv O, Kong Y, Deng L, Shen J. $\mathrm{pH}$-Controlled drug delivery with hybrid aerogel of chitosan, carboxymethyl cellulose and graphene oxide as the carrier. International Journal of Biological Macromolecules. 2017 Oct; 103:248-53.

17. Singh B, Sharma V. Crosslinking of poly(vinylpyrrolidone)/acrylic acid with tragacanth gum for hydrogels formation for use in drug delivery applications. Carbohydrate Polymers. 2017 Feb;157:185-95.

18. Qin S-Y, Zhang A-Q, Cheng S-X, Rong $L$, Zhang $X-Z$. Drug self-delivery systems for cancer therapy. Biomaterials. 2017 Jan;112:234-47.

19. García-Ochoa F, Santos VE, Alcón A. Xanthan gum production: An unstructured kinetic model. 
Enzyme and Microbial Technology. 1995 Mar;17(3):206-17.

20. Cai Y, Deng X, Liu T, Zhao M, Zhao Q, Chen S. Effect of xanthan gum on walnut protein/xanthan gum mixtures, interfacial adsorption, and emulsion properties. Food Hydrocolloids. 2018 Jun;79:391-8.

21. Jang $H Y$, Zhang $K$, Chon BH, Choi $H J$. Enhanced oil recovery performance and viscosity characteristics of polysaccharide xanthan gum solution. Journal of Industrial and Engineering Chemistry. 2015 Jan;21:741-5.

22. Kim M, Park JH. Enantioseparation of chiral acids and bases on a clindamycin phosphatemodified zirconia monolith by capillary electrochromatography. Journal of Chromatography A. 2012 Aug;1251:244-8.

23. Gonzalez G, Sagarzazu A, Cordova A, Gomes ME, Salas J, Contreras L, et al. Comparative study of two silica mesoporous materials (SBA-16 and SBA-15) modified with a hydroxyapatite layer for clindamycin controlled delivery. Microporous and Mesoporous Materials. 2018 Jan;256:251-65.

24. Tan E, Karakus S, Soylu GSP, Birer Ö, Zengin $\mathrm{Y}$, Kilislioglu A. Formation and distribution of $\mathrm{ZnO}$ nanoparticles and its effect on $E$. coli in the presence of sepiolite and silica within the chitosan matrix via sonochemistry. Ultrasonics Sonochemistry. 2017 Sep;38:720-5.

25. Sabbagh N, Akbari A, Arsalani N, EftekhariSis B, Hamishekar H. Halloysite-based hybrid bionanocomposite hydrogels as potential drug delivery systems. Applied Clay Science. 2017 Nov; 148:48-55.

26. Bigham A, Hassanzadeh-Tabrizi SA, Rafienia $M$, Salehi H. Ordered mesoporous magnesium silicate with uniform nanochannels as a drug delivery system: The effect of calcination temperature on drug delivery rate. Ceramics International. 2016 Nov;42(15):17185-91.

27. Parmar A, Sharma S. Engineering design and mechanistic mathematical models: Standpoint on cutting edge drug delivery. TrAC Trends in Analytical Chemistry. 2018 Mar;100:15-35.

28. Siepmann J, Siepmann F. Modeling of diffusion controlled drug delivery. Journal of Controlled Release. 2012 Jul;161(2):351-62.

29. Miastkowska M, Sikora E, Ogonowski J, Zielina M, Łudzik A. The kinetic study of isotretinoin release from nanoemulsion. Colloids and Surfaces A: Physicochemical and Engineering Aspects. 2016 Dec;510:63-8.

30. Kianfar F, Antonijevic M, Chowdhry B, Boateng JS. Lyophilized wafers comprising carrageenan and pluronic acid for buccal drug delivery using model soluble and insoluble drugs. Colloids and Surfaces B: Biointerfaces. 2013 Mar;103:99-106.

31. Gu C, Le V, Lang M, Liu J. Preparation of polysaccharide derivates chitosan-graft-poly $(\varepsilon-$ caprolactone) amphiphilic copolymer micelles for 5-fluorouracil drug delivery. Colloids and Surfaces B: Biointerfaces. 2014 Apr;116:745-50.

32. Vilaça N, Amorim R, Machado AF, Parpot $P$, Pereira MFR, Sardo $M$, et al. Potentiation of 5fluorouracil encapsulated in zeolites as drug delivery systems for in vitro models of colorectal carcinoma. Colloids and Surfaces B: Biointerfaces. 2013 Dec;112:237-44.

33. Rehman F, Ahmed K, Airoldi C, Gaisford S, Buanz A, Rahim A, et al. Amine bridges grafted mesoporous silica, as a prolonged/controlled drug release system for the enhanced therapeutic effect of short life drugs. Materials Science and Engineering: C. 2017 Mar;72:34-41.

34. Liu Y, Shah S, Tan J. Computational Modeling of Nanoparticle Targeted Drug Delivery. Reviews in Nanoscience and Nanotechnology. 2012 Mar $1 ; 1(1): 66-83$.

35. Jarosz M, Pawlik A, Szuwarzyński M, Jaskuła $M$, Sulka GD. Nanoporous anodic titanium dioxide layers as potential drug delivery systems: Drug release kinetics and mechanism. Colloids and Surfaces B: Biointerfaces. 2016 Jul;143:447-54.

36. Bounabi L, Mokhnachi NB, Haddadine N, Ouazib F, Barille R. Development of poly(2hydroxyethyl methacrylate)/clay composites as drug delivery systems of paracetamol. Journal of Drug Delivery Science and Technology. 2016 Jun;33:58-65.

37. Luo H, Ao H, Li G, Li W, Xiong G, Zhu Y, et al. Bacterial cellulose/graphene oxide nanocomposite as a novel drug delivery system. Current Applied Physics. 2017 Feb;17(2):24954.

38. Oun AA, Rhim J-W. Carrageenan-based hydrogels and films: Effect of $\mathrm{ZnO}$ and $\mathrm{CuO}$ nanoparticles on the physical, mechanical, and antimicrobial properties. Food Hydrocolloids. 2017 Jun;67:45-53.

39. Hashemi MM, Aminlari M, Moosavinasab M. Preparation of and studies on the functional properties and bactericidal activity of the lysozyme-xanthan gum conjugate. LWT - Food Science and Technology. 2014 Jul;57(2):594602.

40. Benichou A, Aserin A, Lutz R, Garti N. Formation and characterization of amphiphilic conjugates of whey protein isolate (WPI)/xanthan to improve surface activity. Food Hydrocolloids. 2007 May;21(3):379-91. 
41. Demirbas E, Kobya M, Konukman AES. Error analysis of equilibrium studies for the almond shell activated carbon adsorption of $\mathrm{Cr}(\mathrm{VI})$ from aqueous solutions. Journal of Hazardous Materials. 2008 Jun;154(1-3):787-94.

42. Kapoor A, Yang RT. Correlation of equilibrium adsorption data of condensible vapours on porous adsorbents. Gas Separation \& Purification. 1989 Dec;3(4):187-92.
43. Tanyildizi MŞ. Modeling of adsorption isotherms and kinetics of reactive dye from aqueous solution by peanut hull. Chemical Engineering Journal. 2011 Apr;168(3):1234-40.

44. Knorr D. Dye Binding Properties of Chitin and Chitosan. Journal of Food Science. 1983 Jan;48(1):36-7.

45. Carlough M, Hudson S, Smith B, Spadgenske D. Diffusion coefficients of direct dyes in chitosan. Journal of Applied Polymer Science. 1991 Jun 5;42(11):3035-8. 